\title{
Modeling the swing of mobile loader cranes with anchor outriggers when operating on weak soils
}

\author{
Igor Lagerev ${ }^{1, *}$, Alexander Lagerev ${ }^{1}$, and Vadim Tarichko ${ }^{2}$ \\ ${ }^{1}$ Academician I.G. Petrovskii Bryansk State University, 14 Bezhitskaya st., Bryansk, 241036, Russia \\ ${ }^{2}$ Bryansk Automobile Plant JSC, 1 Staleliteynaya st., Bryansk, 241050, Russia
}

\begin{abstract}
The paper presents a dynamic model illustrating the swing of a mobile machine on a wheeled chassis equipped with a loader crane and anchor outriggers during loading and unloading operations. The model regards the interaction effect of the outrigger anchoring device with weak soil within the system "load - loader crane - chassis - outriggers - anchor devices - soil". Possible variants of single and multiple step soil compaction and changes in its deformation characteristics in the area of the outrigger anchor device implementation are considered. The impact of the gaps formed during soil compaction on the swing parameters of a mobile machine during the swing of the boom of the loader crane is demonstrated as applied to a full-scale crane-manipulator. The rate of chassis tilt angle and swing period of the mobile machine increase during the loader crane operation with an increase in the gaps in the ground. The swing parameters during the initial stage of crane operation gradually increase for soils characterized by multiple compaction until these parameters reach some steady-state values determined by soil stiffness. Awareness of the steadystate value of the crane tilt angle amplitude achieved at the end of the process of weak soil compaction enables to reasonably assess the risk of a mobile machine overturning.
\end{abstract}

\section{Introduction}

Mobile hydraulic cranes on self-propelled wheeled and tracked chassis are widely used in the mining industry to perform a variety of loading and unloading, transport and storage operations $[1,2]$. This is due to the important technical advantages of such cranes being high mobility, operational flexibility, ability to work on sites not equipped in advance $[3,4]$. However, they are adherent to overturning due to the chassis overall stability loss when handling loads of impossibly large weight [5] or due to soil subsidence under one or more outriggers [6, 7]. These accidents account for approximately $45 \%$ of the total number of mobile crane accidents. Therefore, the task of ensuring the stability of mobile cranes is crucial for increasing the reliability and safety of their operation [8-10].

To eliminate such accidents and increase loader cranes stability, outriggers transmitting weight loads to the ground of the working platform are used [11]. When operating on weak soils, outriggers subside unevenly due to soil compaction under the influence of unsteady support reactions $[12,13]$, which leads to crane swinging in the horizontal plane and to dangerous load swinging [14]. Additional anchoring of outriggers when operating mobile cranes on soft soils using screw or pricking devices is an effective way to improve their functional characteristics $[1,15]$. Such anchor outriggers not only provide a more reliable fixation of the crane chassis on the ground but also lead to additional stabilizing moments due to the adhesion force of the anchor's working element (screw or knife) and the soil body at a certain depth.

\section{Mathematical models}

\subsection{Basic mathematical model of anchor outrigger}

Known approaches [9] to assessing the impact of anchor outriggers on the stability of loader cranes are based on research conducted on stable soil during the entire operation time. This does not allow to study the process of interaction between the anchor device and soil in time including the stage when crane loses stability, which is important when creating new effective designs of anchor outriggers. Therefore, in order to increase the reliability of predicting crane operation on soft soils, it is necessary to consider the dynamics of the system "load - loader crane - chassis - anchor outrigger - soil" as a whole regarding the rheological properties of different types of soils.

Figure 1 shows the design diagram of a mobile loader crane with pricking anchor outriggers. The loads indicated in this diagram, acting during crane operation, have the following meaning: $G, Q m, Q s$ are weight loads from the moved load, manipulator and chassis; $W_{G}, W_{m}$, $W$ are wind loads on the moving load, manipulator and chassis; $m_{o 1}, m_{o 2}$ are holding moments of anchor outriggers located outside the tipping edge of the

* Corresponding author: lagerev-bgu@yandex.ru 
supporting contour of the mobile loader crane and along the turnover edge.

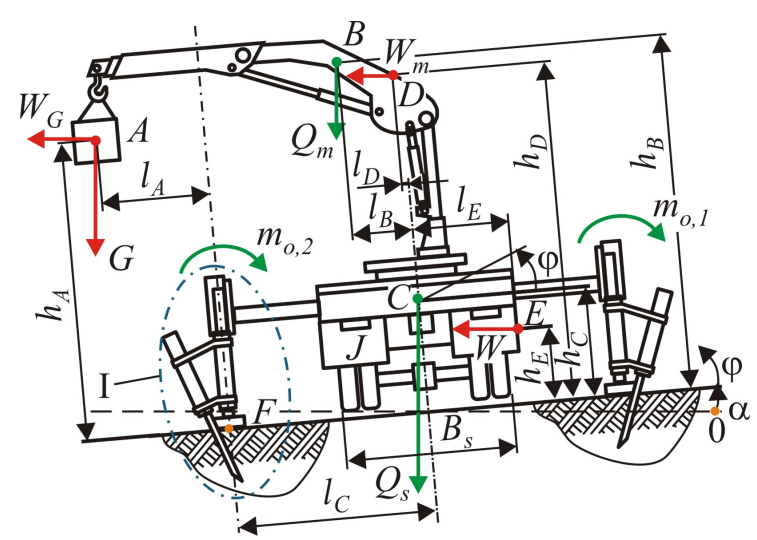

Fig. 1. Design scheme of mobile loader crane

Figure $2 \mathrm{a}$ shows the pricking anchor outrigger, whose design is protected by patents of the Russian Federation $[16,17]$. The anchor outrigger has a hydraulic drive, which lifts the crane chassis when the outrigger rod 2 resting on the sole 3 is moved in the vertical direction, as well as the movement of the working element 5 of the anchor device 4 in the direction II-II with soil pricking 1 . Figure $2 \mathrm{~b}$ shows the possible types of transverse sections of the working element. The crosssection of the working element has longitudinal and transverse ribs used to increase adhesion to the ground.

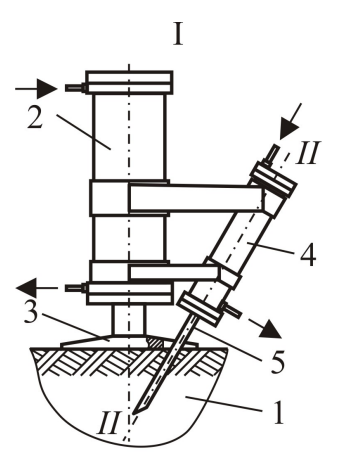

(a)

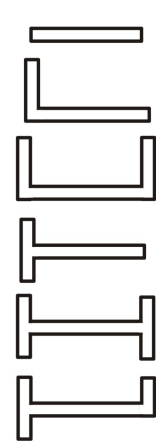

(b)
Fig. 2. (a) anchor outrigger; (b) types of cross-sections of the working element ( 1 - soil; 2 - outrigger; 3 - sole; 4 anchor device; 5 - working element)

The total overturning moment is as follows:

$M_{o v}=M_{o v, G n}+M_{o v, W G}+M_{o v, W s}+M_{o v, W s}$,

where $M_{o v, G}, M_{o v, W G}, M_{o v, W m}, M_{o v, W s}$ are overturning moments from the load weight, wind load on the load, wind load on the metal structure of the loader crane, wind load on the chassis.

When using anchor outriggers, the total stabilizing moment is increased by adding stabilizing moments from all used anchor outriggers and is as follows:

$M_{r s}=M_{r s, Q m}+M_{r s, Q s}+0.5 n_{o}\left(m_{o, 1}+m_{o, 2}\right)$,

where $M_{r s, Q m}, M_{r s, Q s}$ are the stabilizing moments from the weight of the metal structure of the loader crane and the chassis weight; $n_{o}$ is the number of used anchor outriggers.

When the total overturning moment does not exceed the total stabilizing moment, there is no need for additional outrigger anchoring. Therefore, the anchoring device is not involved in ensuring the overall stability of the mobile loader crane. It comes into operation only when the total overturning moment begins to exceed the total stabilizing moment.

The following pullout forces begin to influence the working element of the anchor outrigger

$F_{o, 1}=\Psi_{1}\left(M_{o v}-M_{r s}\right)$

and

$F_{o, 2}=\Psi_{2}\left(M_{o v}-M_{r s}\right)$,

where $\Psi_{j}(\Delta M)$ is transfer function linking force factors $F_{o, j}$ and $\Delta M=M_{o v}-M_{r s}$ (determined by the design and dimensions of the attachment point of the anchor outrigger to the chassis frame).

The mechanisms of occurrence of the stabilizing moments $m_{o 1}$ and $m_{o 2}$ created by anchor outriggers are different. Therefore, they are not the same in size and require the use of different calculation methods. Figure 3 explains the mechanisms of occurrence of these stabilizing moments during soil destruction in the process of pulling out the working element of the anchor outrigger.

For outriggers located outside the overturning edge, the force $F_{o, 1}$ increases monotonically with increasing moment difference $\Delta M$ (figure $3 \mathrm{a}$ ). It reaches its maximum value $F_{o, 1 \max }$ at the moment when the soil's ability to resist the pressure (from the front surface of the working element of the anchor device) caused by the action of the pulling force $F_{o, 1}$ is exhausted. The working element begins a rotary movement in the soil from position I to position II. When it moves, the soil is sequentially destroyed by alternating displacement of its adjacent layers along the shear lines $1-1,2-2, \ldots, 8-8$ with a characteristic soil bulging in front of the front surface of the working element (line $A B$ ). The tilt angle of the shear lines corresponding to the angle of internal friction in the soil, and the shear strength of the soil layers depend on strength properties [18].

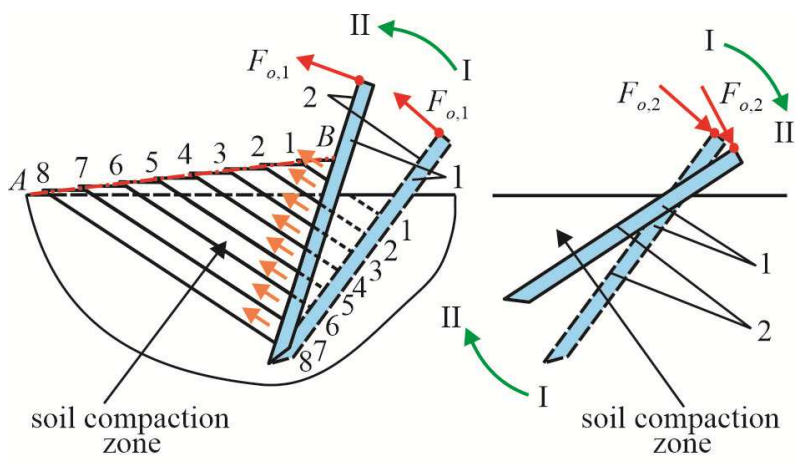

(a)

(b)

Fig. 3. Soil destruction scheme: (a) outrigger outside the overturning edge; (b) outrigger along the overturning edge

( 1 - working element; 2 - front surface of the working element)

When the working element is located under the outrigger's sole, the pattern of soil destruction shown in figure $3 \mathrm{a}$ changes since the sole located on the contact area prevents the free displacement of adjacent soil layers along the shear lines $1-1,2-2, \ldots, 8-8$ and soil 
bulging along the line $A B$. The plain mechanism of soil free destruction caused by displacing its layers only along one set of shear lines changes to a more energyconsuming volumetric mechanism of constrained destruction since a complex spatial displacement of soil layers along the second set of shear lines located approximately perpendicular to the first one also occurs in time. This leads to an increase in the magnitude of the pull-out force generated by the anchor device. The maximum value of the pull-out force $F_{o, 1 \max }$ depends on the strength properties of the soil and the conditions of its destruction. Therefore, it may slightly differ for different outriggers of the same mobile machine.

For outriggers located along the overturning edge, the force $F_{o, 2}$ also increases monotonically with increasing moment difference $\Delta M$ (figure $3 \mathrm{~b}$ ). The rotary movement of the working element in the soil from position I to position II starts when the mobile machine starts overturning. In this case, the working element influences the soil with its rear surface by compacting it. This triggers a resistance force from the side of the compaction soil. The maximum value of the soil resistance force $F_{o, 2 \max }$ and the value of the stabilizing moment $m_{o, 2}$ are also determined by the strength properties of the soil.

The design stabilizing moment $m_{o, j}$ developed by one anchor outrigger is determined by the maximum value of the force $F_{o, j \max }$ and is as follows:

$m_{o, j}=\Delta M_{\max }=\left(M_{o v}-M_{s r}\right)_{\max }=\Psi_{j}^{-1}\left\{F_{o, j \max }\right\}$,

where $\Psi_{j}^{-1}\left\{F_{o, j}\right\}$ is transfer function inverse to transfer function $\Psi_{j}(\Delta M)$.

To assess the efficiency of using the anchor outrigger of the considered design, a computer simulation of the system "load - loader crane - chassis - outrigger anchor devices - soil" in a nonlinear setting based on the finite element method was carried out. The calculation was carried out for the OTML-97 loader crane weighing 2.26 tons based on the KamAZ-65117 chassis weighing 24 tons. The loading moment of the manipulator was 97 $\mathrm{kN} \mathrm{m}$, the maximum outreach was $7.3 \mathrm{~m}$. The outrigger base width was $3.85 \mathrm{~m}$, the distance from the plane of the manipulator installation to the supporting surface was $1.5 \mathrm{~m}$. The influence of the loader crane was regarded using the overturning moment of $97 \mathrm{kN} \mathrm{m}$ applied to the gravity centre of the system. The total weight of the mobile machine and manipulator $257.6 \mathrm{kN}$ in the gravity centre of the computational model is applied vertically downward. The elastic-plastic characteristics of the support surface in the area of the anchor outrigger installation were set using a hardening soil model. The parameters of the soil model for use in the design models of the anchor device are given in [19]. Since the depth of the working element deepening does not exceed $1 \mathrm{~m}$, the change in the rigidity of the soil along the depth can be neglected.

The calculations were carried out for several values of the tilt angle of the working element of the anchor device $\gamma$ in the range from $30^{\circ}$ to $60^{\circ}$ to the horizon. Diagrams of equal dislocation values in a system with a clay base for the tilt angle of the anchor device $\gamma=45^{\circ}$ to the horizon are shown in figure 4.

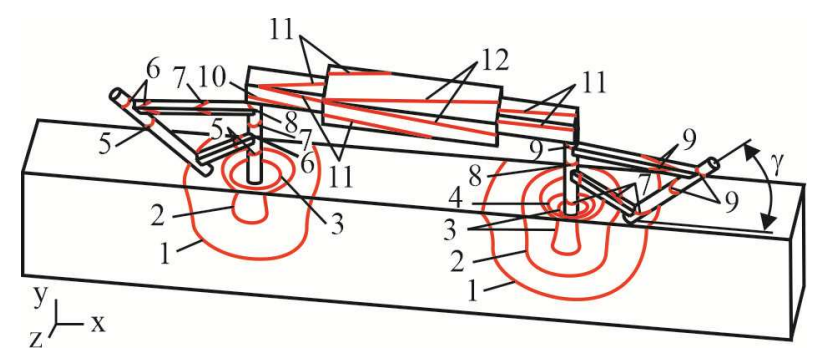

Fig. 4. Lines of equal dislocation: $1-1.2 \mathrm{~mm} ; 2-2.4$ $\mathrm{mm} ; 3$ - $3.6 \mathrm{~mm} ; 4-6.1 \mathrm{~mm} ; 5-8.5 \mathrm{~mm} ; 6-9.7 \mathrm{~mm} ; 7$ - $10.9 \mathrm{~mm} ; 8$ - $12.1 \mathrm{~mm} ; 9$ - $13.3 \mathrm{~mm} ; 10$ - $14.6 \mathrm{~mm}$; $11-15.8 \mathrm{~mm} ; 12-17.0 \mathrm{~mm}$

Figure 5 shows the influence of the tilt angle of the working element of the anchor outrigger on the value of the additional holding moment $m_{o, 1}$ created by it for two types of soil. Calculations have shown that depending on the total mass of the chassis of the mobile machine and the loader crane, the tilt angle of the working element and soil stiffness, the additional stabilizing moment $m_{o, 1}$ can be from $10 \%$ to $40 \%$ of the stabilizing moment $M_{r s, Q m}+M_{r s, Q s}$. For any type of soil, the greatest efficiency of the anchor outrigger is observed at an angle $\gamma$ lying in the range from $30^{\circ}$ to $45^{\circ}$.

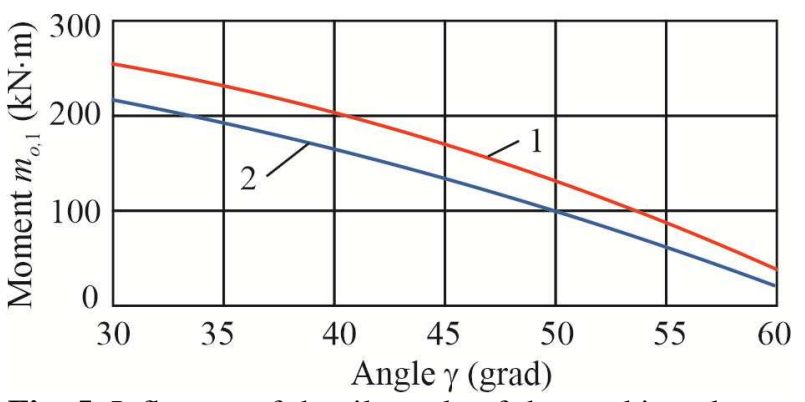

Fig. 5. Influence of the tilt angle of the working element of the anchor outrigger on the additional stabilizing moment created by it ( 1 - clay; 2 - sand)

\subsection{Modified mathematical model of anchor outrigger}

The considered basic mathematical model adequately reflects the physical phenomena observed when loader cranes operate on soils with high stiffness characteristics. However, the basic model requires refinement in the case of weak soils due to the formation of sufficiently large wedge-shaped gaps in the soil (figure 3a), which can affect the dynamics and endurance of the nodes of the supporting iron of the loader crane during operation [20].

Field observations have showed that with partial soil compaction in the area of a pricking working element implementation, gaps are formed between it and the soil, which leads to swinging (unsteady tilting) of the loader crane under a time-variable difference in the values of the overturning and stabilizing moments. There are two options for soil compaction: single step and multiple step (figure 6). A single step compaction at the initial stiffness of the soil $c_{a g}=c_{a g 0}$ occurs in the first cycle of contact between the working element and the soil with 
the formation of a wedge-shaped gap $\delta_{1}$ (figure 6a). The soil does not compact, thus, its stiffness $c_{a g}$ in the area of the working element remains practically constant and equal to $c_{a g 1}$. When the boom of the loader crane is rotated relative to the gravity center of the chassis at some time intervals of approximately equal duration $\Delta t_{\delta}$, the anchor device does not rest on the edge of the compacted soil and $c_{a g}=0$. The duration of $\Delta t_{\delta}$ is determined by the time required for the working element to select the gap $\delta_{1}$. Staged soil compaction (figure $3 \mathrm{~b}$ ) takes place over several successive cycles. It occurs with a gradual increase in the gap $\delta_{k}$ and soil stiffness $c_{a g k}$ at each $k$-th cycle $\left(k=1 \ldots N_{u}\right.$, where $N_{u}$ is the number of compaction cycles). As the gap grows, the duration $\Delta t_{\delta k}$ also increases. After several compaction cycles, the stiffness of the soil stabilizes at the value $c_{a g N u}$.
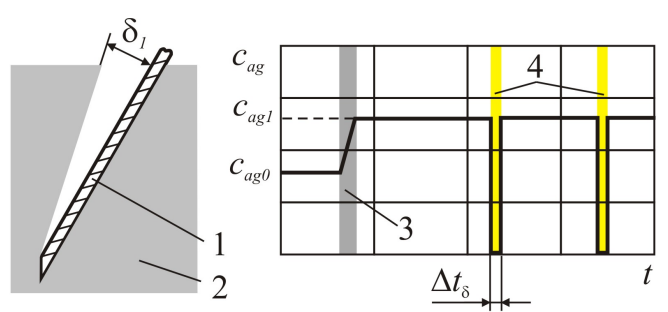

(a)
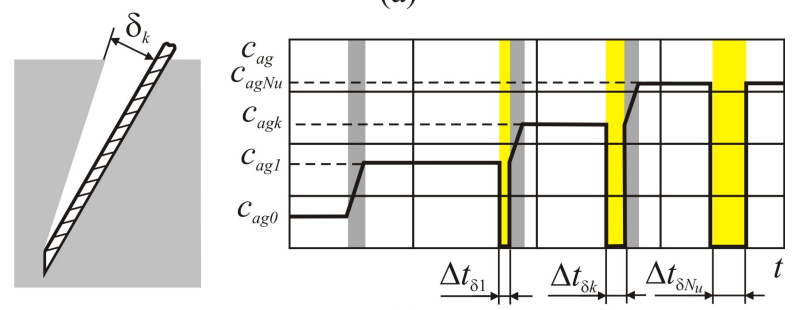

(b)

Fig. 6. Options for soil compaction in the area of the outrigger anchor device: (a) single; (b) stepwise (1 working element; 2 - soil; 3 - stage of soil compaction; 4 - process of choosing a gap when turning the loader crane)

Thus, the basic mathematical model of the outriggersoil interaction can be modified by adding a model of the anchor device-soil interaction. The design diagram of the mathematical model for studying the dynamic processes of swinging a mobile crane with regards to the anchor device influence is shown in figure 7 . When the crane operates, soil compaction occurs on both sides of the working element. Therefore, let us denote the gap arising from such a rotation of the loader crane, when the considered $i$-th outrigger is outside the turnover angle as $\delta_{k, i(+)}$, and when along the tipping angle - as $\delta_{k, i(-)}$.

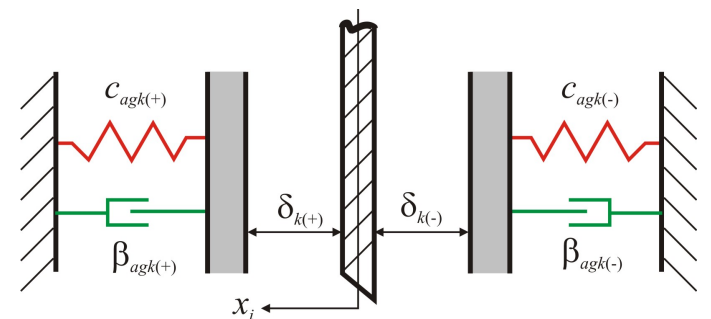

Fig. 7. Design scheme of outrigger anchor device
When the working element is supported by the soil, a force $f_{o, i}$ arises in the $i$-th anchor outrigger and leads to an additional stabilizing moment $m_{o, i}$. Depending on the change in the angle $\varphi$, the outrigger can alternately be located either along or outside the tipping edge. Therefore, during crane operation, additional forces $F_{o, i}$ and stabilizing moments $m_{o, i}$ are variable:

- if the outrigger is outside the tipping edge

$F_{o, i}=c_{a g k, i(+)} x_{i}+\beta_{a g k, i(+)} \dot{x}_{i}$,

$m_{o, i}=F_{o, i} r_{o, i}$

- if the outrigger is along the tipping edge

$F_{o, i}=c_{a g k, i(-)} x_{i}+\beta_{a g k, i(-)} \dot{x}_{i}$,

$m_{o, i}=F_{o, i} r_{o, i}$

where $c_{a g k, i}, \beta_{a g k, i}$ are soil stiffness and the coefficient of energy dissipation by the soil for the $i$-th anchor support; $x_{i}, \dot{x}_{i}$ is a coordinate relative to the initial position and speed of the working element of the $i$-th anchor support; $r_{o, i}$ is moment $\operatorname{arm} F_{o, i}$.

The mathematical model for studying the dynamic processes of a mobile crane swinging wih regards to the influence of the anchor device is a system of two equations of the following form:

$i=n_{o}$

$J \varphi=M_{o v, G n}+M_{o v, W G}+M_{o v, W s}+M_{o v, W s}-M_{r s, Q m}-M_{r s, Q s}-\Sigma m_{o, i} ;$

$i=1$

$\delta_{k, i(-)} \leq x_{i}(\varphi) \leq \delta_{k, i(+)}$,

where $J$ is moment of inertia of the chassis, crane and load reduced to the gravity center of the chassis; $\varphi$ is chassis tilt angle.

In the first equation of the mathematical model, the coordinates $x_{i}$ depend on the tilt angle of the chassis in the horizontal plane $\varphi$. Generally, the gaps $\delta_{k, i(-)}$ and $\delta_{k, i(+)}$ for different outriggers may not be the same in magnitude, which will additionally cause some turn of the chassis in the horizontal plane. However, due to its insignificance, it can be assumed that for all outriggers outside and along the overturning edge $\delta_{k, i(-)}=\delta_{k, i(+)}$.

In real conditions, the values of the gaps $\delta_{k, i(-)}$ and $\delta_{k, i(+)}$ (+) can be different for all supports due to the random dispersion of the the soil mechanical properties. This will cause an additional small turn of the chassis in the horizontal plane. Therefore, when constructing a mathematical model, we will assume that for all supports outside the overturning edge, the values of the gaps $\delta_{k, i(-)}$ snd $\delta_{k, i(+)}$ are equal. We introduce a similar assumption for all supports located along the tipping edge.

The impact of outriggers on the soil affects the final value of its stiffness $c_{a g, i}$ in the zone of the $i$-th anchor device penetration. The magnitude of the impact is determined only by the magnitude of the support reactions from the outriggers, since the chassis suspension does not contact with the ground. Thus, the suspension of the base chassis does not operate. Figure 8 shows the design diagram of the support loop of a mobile crane to determine the support reactions for each of the four outriggers.

The loader crane is located on the longitudinal axis of the mobile chassis at point $O$. The weight of the load $G$ and the loader crane $Q_{m}$ is applied at their common gravity center $E_{1}$ at a distance $R$ from the point $O$, the 
weight of the chassis $Q_{s}$ is at the point $E_{1}$. When the loader crane is rotated through an angle $\alpha$, the chassis is subject to the following moments:

$M_{x}=G R \sin \alpha$;

$M_{y}=G\left(R \cos \alpha+h_{A} \sin \varphi\right)+M_{o v, W G}+M_{o v, W m}+M_{o v, W s}$.

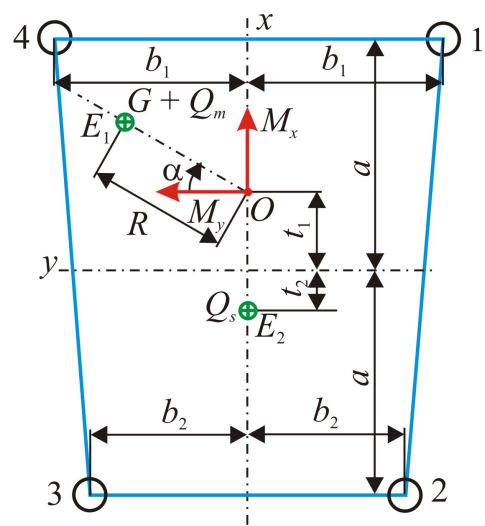

Fig. 8. Design diagram of support contour of mobile loader crane to determine support reactions of anchor outriggers

The distance to the common gravity center of the load and the loader crane $R$ and the distance between the planes of the gravity centers of the chassis and the manipulator $l_{B}$ (figure 9) are as follows:

$R=\left(Q_{m} l_{B}+G L\right) /\left(Q_{m}+G\right)$;

$l_{B}=\left[\Sigma Q_{m, j}\left(u_{j}+u_{0, j}^{j}=N_{s} \cos \varepsilon_{j}-v_{0, j}^{\prime} \sin \varepsilon_{j}\right)\right] / Q_{m}$,

where $Q_{m, j}$ is the weight of the $j$-th link of a loader crane; $u_{j}$ is the horizontal coordinate of the $j$-th link closest to the base of the articulated joint in the global coordinate system $u O v$, whose beginning is at the point of the loader crane installation $O ; u_{0, j}^{\prime}, v_{0, j}^{\prime}$ are coordinates of the gravity center in the local coordinate system $u_{j}^{\prime} O_{j} v_{j}^{\prime}$, connected with $j$-th link; $\alpha_{j}$ is current orientation angle of the $j$-th link; $N_{s}$ is the number of links of a loader crane.
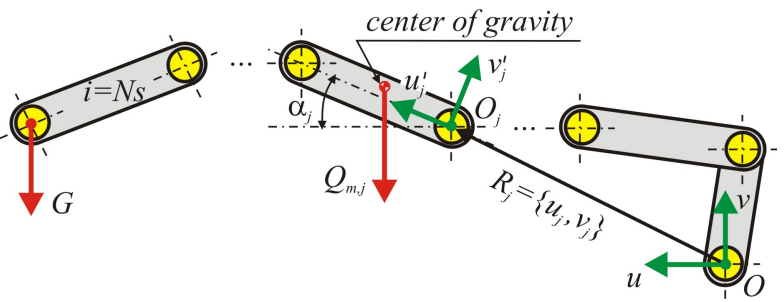

Fig. 9. Distance calculation scheme $l_{B}$

Support reactions in each $i$-th outrigger are determined by the following dependencies:

$$
\begin{aligned}
& R_{1}=\frac{G+Q_{m}}{4}\left(1+\frac{t_{1}}{a}\right)+\frac{Q_{s}}{4}\left(1-\frac{t_{2}}{a}\right)+\frac{M_{x}}{4 a}-\frac{M_{y} b_{1}}{2\left(b_{1}+b_{2}\right)} ; \\
& R_{2}=\frac{G+Q_{m}}{4}\left(1-\frac{t_{1}}{a}\right)+\frac{Q_{s}}{4}\left(1+\frac{t_{2}}{a}\right)-\frac{M_{x}}{4 a}-\frac{M_{y} b_{2}}{2\left(b_{1}+b_{2}\right)} ; \\
& R_{3}=\frac{G+Q_{m}}{4}\left(1-\frac{t_{1}}{a}\right)+\frac{Q_{s}}{4}\left(1+\frac{t_{2}}{a}\right)-\frac{M_{x}}{4 a}+\frac{M_{y} b_{2}}{2\left(b_{1}+b_{2}\right)} ; \\
& R_{4}=\frac{G+Q_{m}}{4}\left(1+\frac{t_{1}}{a}\right)+\frac{Q_{s}}{4}\left(1-\frac{t_{2}}{a}\right)+\frac{M_{x}}{4 a}+\frac{M_{y} b_{1}}{2\left(b_{1}+b_{2}\right)},
\end{aligned}
$$

where $b_{1}, b_{2}$ are half-length of the support contour in the area of the front and rear outriggers.

\section{Modeling results}

The results of modeling the swing of the mobile loader crane Fassi M30A.13 on the wheeled chassis GAZ-Next are shown in figure 10 . When the manipulator arm rotates around the vertical axis at a constant angular velocity, the chassis tilt angle $\varphi$ changes according to a periodic law with an amplitude $\Delta \varphi_{\max }$ corresponding to the choice of gaps $\delta_{k, i(-)}$ or $\delta_{k, i(+)}$. The values of external loads are selected from the condition that the absence of anchoring of the outriggers leads to a loss of stability of the mobile crane. A model of five-fold soil compaction was used with the parameters $c_{a g 0}=70 \mathrm{mN} / \mathrm{m}, c_{a g 1}=$ $1.5 c_{a g 0}$. As the analysis of the graphs in figure 10 shows, during the time required to perform five cycles of the reciprocating movement of the crane arm with the load, there occurs a non-linear magnitude and gradual increase in ground gaps, which leads to an increase in the amplitude of the crane tilt angle $\Delta \varphi_{\max }$ and the swing period.

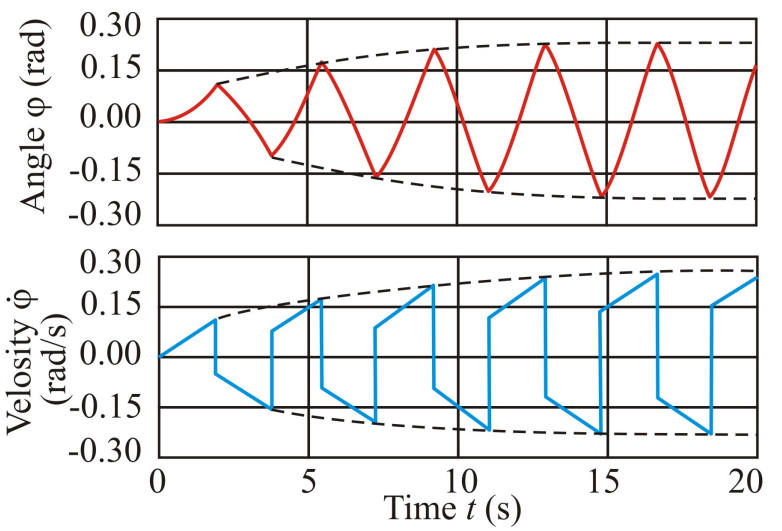

(a)

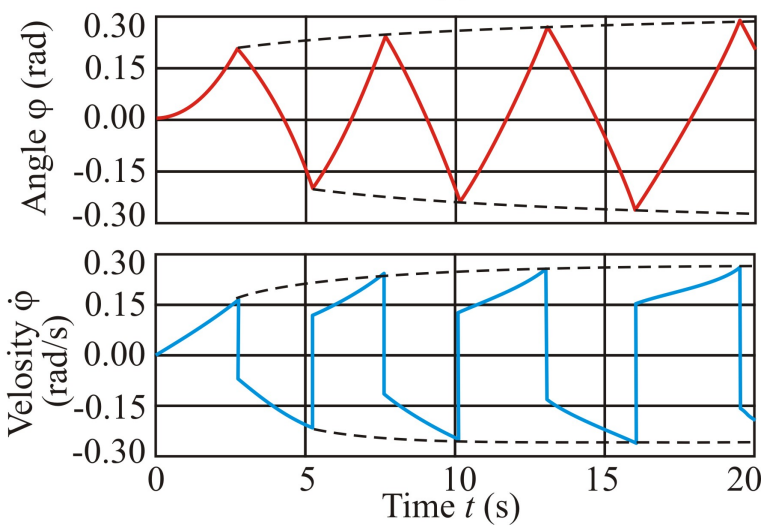

(b)

Fig. 10. Results of modeling dynamics of loader crane: (a) ground gaps correspond to $\Delta \varphi_{\max }=0.1 \mathrm{rad}$; (b) ground clearances correspond to $\Delta \varphi_{\max }=0.15 \mathrm{rad}$

\section{Conclusion}

The developed mathematical dynamic model of a mobile loader crane swinging during its operation and with the reciprocating movement of the manipulator boom with 
the transported load regarding the effects of interaction between anchor outriggers and the weak soil of the support base enables to simulate the experimentally revealed gradual compaction of the soil in the area of introduction of the working element of the outrigger anchor device. With an increase in the gaps $\delta_{k, i(-)}$ and $\delta_{k, i(+)}$ in the ground, the rate of change of the chassis tilt angle $\varphi$ and the period of swinging of the mobile machine during loader crane operation increase. Therefore, for soils characterized by multiple compaction, the swing parameters during the initial stage of crane operation (during the first $N_{u}$ compaction cycles) gradually increase until they reach some steadystate values determined by the soil stiffness $c_{a g N u}$.

Knowing the steady-state value of the amplitude of the crane tilt angle $\Delta \varphi_{\max }$ achieved at the end of the process of weak soil compaction contributes to a more reasonable assessment of the risk of a mobile machine overturning.

To improve the accuracy of modeling, the following is necessary:

- to continue experimental studies of the interaction between the soil of the support base and the working elements of the outrigger anchor devices;

- to experimentally clarify the values $c_{a g}$ for different types of soils at different values of vertical loads;

- consider the possibility of differences in the values of $\delta_{k, i(+)}$ and $\delta_{k, i(-)}$ for all supports causing an additional rotation of the base machine in the horizontal plane.

\section{Acknowledgements}

The study was supported by President Grant for Government Support of Young Russian Scientists No. MD-422.2020.8

\section{References}

1. I.A. Lagerev, A.V. Lagerev, IOP Conf. Series: Earth and Environ. Sci. 194, 032015 (2018)

2. J.J. Olt, V.V. Maksarov, V.A. Krasnyy, J. of Mining Institute 235, 70-77 (2019)

3. S. Bell, Mobile Crane (Cherry Lake Publishing, Ann Arbor, 2018)

4. I.A. Lagerev, A.V. Lagerev, Lect. Notes in Mechanical Eng. 0(9783319956299), 2283-2293 (2019)

5. Mobile cranes overturning on construction sites (HSB Engineering Insurance Ltd., Munich, 2014).

6. D. Duerr, Mobile crane support handbook (Levare Press, Houston, 2019)

7. D.A. Potakhov, Nauchno-tekhnicheskiy vestnik Bryanskogo gosudarstvennogo universiteta 3, 426433 (2020)

8. A.A. Shaikh, J. of Theoret. and Appl. Mech. 1, 21927 (2015)

9. S.-L. Jeng, C.-F. Yang, W.-H. Chieng, Mechanics Based Design of Structures and Machines 38(2), 145-170 (2010)
10. I. Doci, N. Lajqi, Sh. Lajqi, IREME 12(2), 135-141 (2018)

11. D. Rupar, Ju. Hladnik, B. Jerman, $F M E$ Transactions 44, 291-297 (2016)

12. E. Jarzębowska, A. Urbaś, K. Augustynek, J. Vib. Eng. Technol. 8, 337-350 (2020)

13. G. Romanello, Mechanics Based Design of Structures and Machines 47 (2020)

14. D. Cekus, P. Kwiaton, Mechanism and machine theory 153, 104011 (2020)

15. I.S. Bychkov, Vestnik SibADI 3, 7-11 (2017)

16. Patent RU No.165312, B66C 23/64 (2016)

17. Patent RU No.186456, B66C 23/78 (2018)

18. R.F. Craig, Craig's Soil Mechanics (Spon Press, New York, 2004)

19. B.I. Dalmatov, Soil Mechanics, Bases and Foundations (Stroyizdat, Leningrad, 1988)

20. I.A. Lagerev, A.V. Lagerev, IOP Conf. Series: Earth and Environ. Sci. 194(4) 042012 (2018) 